Jurnal Farmamedika Vol. 5, No. 1, Juni 2020

\title{
PENGARUH FRAKSINASI BUNCIS (PHASEOLUS VULGARIS L.) TERHADAP PENURUNAN KADAR KOLESTEROL TIKUS PUTIH (RATTUS NORVEGICUS L.) YANG HIPERKOLESTEROLEMIA
}

\author{
Lilik Sulastri $^{1 *}$, Putri Syafalia ${ }^{1}$, Achmad Fauzi Isa $^{1}$ \\ Program Studi S1 Farmasi Sekolah Tinggi Teknologi Industri dan Farmasi Bogor \\ Korespondensi : liliksulastri28@gmail.com
}

\begin{abstract}
ABSTRAK
Hiperlipidemia merupakan suatu keadaan meningkatnya kadar lipid darah yang ditandai dengan meningkatnya kadar kolesterol total, Low Density Lipoprotein (LDL), dan trigliserida dalam darah yang melebihi batas normal. Sampai saat ini telah banyak obat yang digunakan untuk penanganan hiperlipidemia baik obat sintetik dan obat herbal. Salah satu obat herbal yang telah digunakan oleh masyarakat Indonesia adalah buncis (Phaseolus vulgaris L.). Tujuan penelitian ini adalah untuk mengetahui pengaruh beberapa ekstrak ( $n$-heksan, etilasetat dan air) buah buncis terhadap penurunan kadar kolesterol tikus jantan galur Sprague Dawley yang telah diinduksi kuning telur puyuh, PTU 0,02\% dan asupan pakan aterogenik selama 14 hari. Pengukuran kadar kolesterol dilakukan secara enzimatis dengan alat kolesterolmeter Easy Touch $^{\circledR}$. Hasil fraksinasi ekstrak etanol buncis dengan pelarut $n$-heksan, etil asetat, dan air diujikan selama 7 hari dengan dosis 50 $\mathrm{mg} / \mathrm{kg}$ BB diperoleh fraksi air sebagai fraksi yang paling aktif menurunkan kadar kolesterol darah. Pada uji lanjutan fraksi air dilakukan terhadap 5 kelompok perlakuan ( $5 \times 5$ ekor), yaitu kelompok 1 (Na CMC 0,5\%) sebagai kontrol negatif, kelompok 2 (simvastatin 0,18 mg/200 g BB) sebagai kontrol positif dan variasi dosis fraksi air $50 \mathrm{mg} / \mathrm{kg} \mathrm{BB}, 100 \mathrm{mg} / \mathrm{kg}$ BB serta $150 \mathrm{mg} / \mathrm{kg} \mathrm{BB}$ (kelompok 3, 4, dan 5). Selama 21 hari perlakuan tikus tetap diberikan pakan aterogenik dan pengukuran kadar kolesterol dilakukan pada hari ke 0, 14, 21, 28, dan 35. Hasil uji lanjutan menunjukkan bahwa fraksi air ekstrak buncis pada dosis 50 dan $100 \mathrm{mg} / \mathrm{kg}$ BB tidak memiliki perbedaan yang nyata dengan simvastatin, sedangkan pada dosis $150 \mathrm{mg} / \mathrm{kg}$ BB menunjukkan perbedaan yang nyata dangan simvastatin dalam menurunkan kadar kolesterol.
\end{abstract}

Kata kunci: hiperkolesterolemia, Phaseolus vulgaris L., fraksinasi, pakan aterogenik

\begin{abstract}
Hyperlipidemia is a condition of increased blood lipid levels characterized by increased levels of total cholesterol, Low Density Lipoprotein (LDL), and triglycerides in the blood exceed normal limits. One of herbal medicines used by Indonesian people is green beans (Phaseolus vulgaris L.). The aim of this research was to know the effect of some extracts (n-hexane, ethylacetate and water) of beans on decreasing cholesterol levels of Sprague Dawley male rats induced by quail egg yolk, PTU $0.02 \%$ and atherogenic feed intake for 14 days. Measurement of cholesterol levels was done enzymatically using cholesterolmeter Easy Touch ${ }^{\circledR}$. Our preliminary results showed that among the three fractions tested (n-hexane, ethyl acetate and water) for 7 days at a dose of 50 $\mathrm{mg} / \mathrm{kgBW}$, the most effective fraction in lowering the cholesterol level was the water fraction.. The water fraction was then given to 5 groups of rats (each consisted of 5 rats); group 1 (Na CMC $0,5 \%$ ) as negative control, group 2 (simvastatin $0.18 \mathrm{mg} / 200 \mathrm{~g} \mathrm{BW}$ ) as a positive control and variety of doses water fraction $50 \mathrm{mg} / \mathrm{kg} \mathrm{BW}, 100 \mathrm{mg} / \mathrm{kg} \mathrm{BW}$ also, and $150 \mathrm{mg} / \mathrm{kg} \mathrm{BB}$ (group 3, 4, and 5) respectively. The atherogenic feed was given for 21 days and the cholesterol levels was measured at days 0th, 14th, 21st, 28th, and 35th. Results showed that there was no significant difference in the effect of 50 and $100 \mathrm{mg} / \mathrm{kgBW}$ with that of simvastatin ( $>0.05$ ); on the other hand dose $150 \mathrm{mg} / \mathrm{kgBW}$ showed a significant difference with simvastatin for in decreasing the cholesterol levels.
\end{abstract}

Key word: hypercholesterolemia, Phaseolus vulgaris L., fractionation, atherogenic feed 


\section{PENDAHULUAN}

Makanan siap saji yang mengandung lemak jenuh berlebih merupakan salah satu penyebab meningkatnya kadar kolesterol. Hiperkolesterolemia merupakan gangguan metabolisme kolesterol yang terjadi karena adanya peningkatan kadar kolesterol LDL dalam darah yang melebihi batas normal $[1,2]$. Hiperkolesterolemia berdampak pada penyakit jantung koroner $(\mathrm{PJK})$ dan penyakit kardiovaskuler, dan sangat erat kaitannya dengan konsumsi lemak dan kolesterol yang terdapat di dalam makanan asal hewan, seperti hati, ginjal, dan kuning telur. Pengobatan hiperkolesterolemia membutuhkan waktu yang lama dan biaya yang tidak sedikit. Pengobatan pun harus disertai dengan pola makan yang baik. Bagi sebagian besar orang, hal ini sulit dilakukan.

Obat yang biasa digunakan oleh masyarakat untuk menurunkan kadar kolesterol salah satunya adalah simvastatin. Senyawa ini

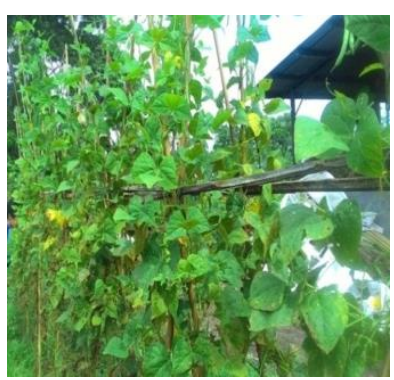

(A) bekerja dengan menghambat HMG-CoA reduktase secara kompetitif pada proses sintesis kolesterol di hati. Namun obat ini memiliki efek samping berupa penyakit otot, reumatik otot, dan radang sendi [3]. Oleh karena itu diperlukan pengobatan tradisional dengan bahan alam yang lebih murah dan lebih aman, tetapi memiliki efektifitas yang sama dengan simvastatin yang beredar di pasaran.

Salah satu tanaman yang dimanfaatkan sebagai obat adalah buncis (Phaseolus vulgaris L.). Kandungan fitokimia dalam serbuk ekstrak buncis terdiri dari alkaloid, flavonoid, fenol, saponin dan steroid/triterpenoid [4]. Buncis juga mengandung senyawa polifenol, asam fenolat seperti asam kumarat [5] glikosida dan metabolit sekunder yang lain yang memiliki aktivitas sebagai antioksidan, antikanker, antidiabetes antimikroba, antiinflamasi [6,7] dan penyakit degenerative lain hingga kardiovaskular [8].

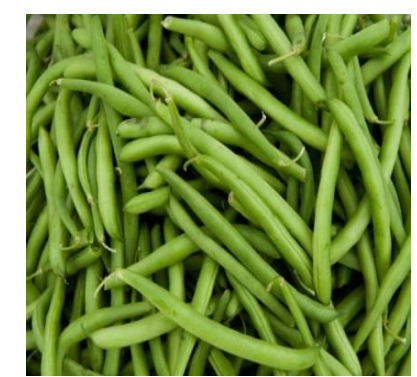

(B)

Gambar 1. Tanaman Buncis (Phaseolus vulgaris L.)

(A) Tanaman buncis utuh, dan (B) Buah buncis

Buncis mengandung senyawa-senyawa aktif yang dapat menurunkan kadar kolesterol diantaranya flavonoid, alkaloid, dan fitosterol [9]. Kandungan senyawa yang terdapat dalam ekstrak etanol dan ekstrak air mengandung stigmasterol yang merupakan golongan fitosterol [10]. Ekstrak etanol buncis dosis 50 $\mathrm{mg} / \mathrm{kg}$ BB dalam menurunkan kolesterol hampir setara bahkan lebih baik dari simvastatin $0,18 \mathrm{mg} / 200 \mathrm{~g}$ BB pada tikus wistar, dengan persentase penurunan sebesar $23,88 \%$ untuk ekstrak buncis $50 \mathrm{mg} / \mathrm{kg}$ BB dan $22,69 \%$ untuk simvastatin [9].

Tujuan penelitian ini adalah untuk mengetahui pengaruh beberapa ekstrak ( $n$ heksan, etilasetat dan air) buah buncis terhadap penurunan kadar kolesterol tikus jantan galur
Sprague Dawley yang telah diinduksi kuning telur puyuh, PTU $0,02 \%$ dan asupan pakan aterogenik selama 14 hari.

\section{BAHAN DAN METODE Bahan}

Bahan yang digunakan dalam penelitian ini adalah buncis, etanol 96\%, $n$-heksan, etil asetat, akuades, $\mathrm{Na} \mathrm{CMC}, \mathrm{HCl}$ pekat, amil alkohol, $\mathrm{CHCl}_{3}, \mathrm{H}_{2} \mathrm{SO}_{4} 2 \mathrm{~N}$, pereaksi Dragendorff, pereaksi Meyer, pereaksi Wagner, $\mathrm{FeCl}_{3}, \mathrm{HCl} 2$ $\mathrm{M}$, serbuk logam $\mathrm{Mg}$, kuning telur puyuh, tablet simvastatin $10 \mathrm{mg}$ (Kimia Farma), tablet propiltiourasil (PTU) 100 mg (Dexa Medika), alumunium foil, kertas saring, lemak kambing, dan pakan pellet HI-GRO 551. 
16 | Lilik Sulastri et al., (Pengaruh Fraksinasi Buncis (Phaseolus vulgaris L.) ...)

Alat

Alat yang digunakan dalam penelitian ini adalah blender, ayakan 40 mesh, rotary evaporator $(I K A)^{\circledR}$, desikator, oven $(E l o s)^{\circledR}$, cawan porselen, alat gelas, statif dan klem, corong pisah, waterbath, termometer, timbangan analitik $(A C I S)^{\circledR}$, lampu spiritus, kaki tiga, kasa kawat, mortir, sonde tikus, spuit 1 cc $(\text { Terumo })^{\circledR}$, kolesterolmeter $(\text { Easy Touch })^{\circledR}$, strip kolesterol (Easy Touch) ${ }^{\circledR}$, gunting steril, alkohol 70\% swab, kandang tikus dan GCMSQP2010 ULTRA.

\section{Ekstraksi}

Sebanyak $300 \mathrm{~g}$ simplisia serbuk buncis dimaserasi dengan 1 L etanol $96 \%$ dan didiamkan selama 24 jam. Kemudian maserat dipisahkan dari ampasnya, dan ampas diremaserasi dengan mengganti pelarut etanol 96\% yang baru, didiamkan selama 24 jam lalu dipisahkan maserat dari ampasnya. Remaserasi dilakukan 2 kali dan ketiga maseratnya dicampur dalam satu bejana selanjutnya diuapkan dengan menggunakan rotary evaporator dan dilanjutkan dengan penguapan menggunakan waterbath hingga diperoleh ektrak kental.

\section{Fraksinasi}

Ekstrak kental buncis yang diperoleh difraksinasi dalam corong pisah dengan 3 macam pelarut, yaitu: $n$-heksan, etil asetat dan akuades. Cara kerjanya ekstrak kental buncis diencerkan terlebih dahulu dengan akuades sebanyak $200 \mathrm{~mL}$, diaduk hingga homogen. Cara ini dilakukan sebanyak tiga kali pengulangan hingga diperoleh $600 \mathrm{ml}$. Kemudian dibagi menjadi dua masing-masing sebanyak $300 \mathrm{ml}$ dan dimasukkan ke dalam corong pisah $500 \mathrm{ml}$, dan dilakukan fraksinasi dengan $300 \mathrm{ml}$ n-heksan dan $300 \mathrm{ml}$ etil asetat dengan tiga kali pengulangan. Hasil fraksinasi dari masing-masing pelarut diuapkan dengan rotary evaporator hingga diperoleh fraksi kental $n$-heksan, etil asetat dan air. Fraksi tersebut diidentifikasi senyawa dengan uji fitokimia, diuapkan dengan waterbath, dihitung rendemen dan diuji aktivitas penurunan kolesterol.

\section{Uji Fitokimia}

Uji fitokimia yang dilakukan yaitu alkaloid, flavonoid, tanin, saponin, steroid dan triterpenoid (Harborne, 1987).

\section{Pembuatan Pakan Aterogenik}

Pakan aterogenik dibuat dengan mencampurkan $100 \mathrm{~g}$ lemak kambing (10\%) dan 50 g kuning telur (5\%) dalam 1000 g pakan standar. Sebelum dicampur dengan pakan standar, lemak kambing dipanaskan dahulu hingga mencair, dan kuning telur diambil dari telur yang telah direbus (Gani et al., 2013). Pada penelitian ini pakan standar diganti dengan pakan pellet HI-GRO 551 dan telur yang digunakan adalah telur puyuh dengan kandungan kolesterol tertinggi.

\section{Penginduksian pada tikus}

Induksi Kuning Telur Puyuh diberikan secara oral menggunakan sonde. Diberikan dalam $1 \mathrm{ml}$ larutan kuning telur puyuh yang setara dengan $30 \mathrm{mg}$ kuning telur puyuh dan $10,78 \mathrm{mg}$ kolesterol. Induksi Propiltiourasil (PTU) $0,02 \%$ diberikan secara oral dengan dosis $10 \mathrm{ml} / \mathrm{kg}$ BB tikus dalam suspensi $\mathrm{Na}$ CMC $0,5 \%$.

\section{Pembuatan Sediaan Uji}

Pembuatan Suspensi Na CMC 0,5\% (Kontrol Negatif) $250 \mathrm{mg} \mathrm{Na}$ CMC ditaburkan di atas air panas $5 \mathrm{~mL}$ dalam lumpang panas dan dibiarkan selama 15 menit. Kemudian digerus sampai homogen, lalu ditambahkan akuades sampai $50 \mathrm{~mL}$. Pembuatan Suspensi Simvastatin (Kontrol Positif) Na CMC $250 \mathrm{mg}$ ditaburkan di atas air panas $5 \mathrm{~mL}$ dalam lumpang panas dan dibiarkan selama 15 menit. Kemudian digerus, dimasukkan 1 tablet simvastatin $10 \mathrm{mg}$ yang telah dihaluskan gerus sampai homogen, lalu ditambahkan akuades sampai $50 \mathrm{~mL}$. Pembuatan Suspensi Hasil Fraksinasi Ekstrak Buncis, $125 \mathrm{mg}$ Na CMC yang sudah dikembangkan, ditambahkan hasil fraksi ekstrak buncis yang sudah ditimbang sesuai dengan dosis yang direncanakan gerus homogen, lalu ditambahkan akuades sampai 25 $\mathrm{mL}$. Ekstrak yang sudah disuspensikan kemudian dimasukkan ke dalam tubuh tikus menggunakan sonde oral.

\section{Uji Aktivitas Penurunan Kadar Kolesterol}

Hewan uji dikelompokkan menjadi 3 kelompok terdiri dari 3 ekor tikus putih yang telah diadaptasi selama 1 minggu, dan dilakukan pengukuran kadar kolesterol sebelum diinduksi. Setelah itu, tikus diberi pakan aterogenik setiap hari dengan berat bobot pakan \pm 20 g per ekor tikus dan air ad libitum. Setiap kelompok diinduksi dengan larutan kuning telur 
puyuh $1 \mathrm{ml}$ dan induksi PTU 0,02\% $10 \mathrm{ml} / \mathrm{kg}$ sampai perlakuan selesai. Kemudian dilakukan pengukuran kadar kolesterol kembali setelah diinduksi. Selanjutnya diberikan perlakuan pada hari ke-14 untuk masing-masing kelompok yaitu, kelompok (I) diberikan fraksi $n$-heksan $50 \mathrm{mg} / \mathrm{kg} \quad \mathrm{BB}$, kelompok (II) diberikan fraksi etil asetat $50 \mathrm{mg} / \mathrm{kg} \mathrm{BB}$, dan kelompok (III) diberikan fraksi air $50 \mathrm{mg} / \mathrm{kg}$ BB. Perlakuan diberikan selama 7 hari dengan pengukuran kadar kolesterol setiap hari yaitu hari ke-14 sampai ke-21. Fraksi yang memiliki aktivitas tertinggi dalam menurunkan kadar
BB selama 14 hari, pakan aterogenik diberikan kolesterol dilakukan uji lanjutan. Uji lanjutan diberikan terhadap 5 kelompok dengan suspensi $\mathrm{Na}$ CMC 0,5\% $1 \mathrm{ml}$ (kontrol negatif), simvastatin $0,18 \mathrm{mg} / 200 \mathrm{~g} \quad \mathrm{BB}$ ( kontrol positif), fraksi air dosis $50 \mathrm{mg} / \mathrm{kg} \quad \mathrm{BB}$ (kelompok I), $100 \mathrm{mg} / \mathrm{kg}$ BB (II) dan 150 $\mathrm{mg} / \mathrm{kg}$ BB (III). Perlakuan diberikan selama 21 hari dengan interval pengukuran kadar kolesterol selama 7 hari, yaitu pada hari ke-21, 28, dan 35 dengan menggunakan alat kolesterolmeter digital Easy Touch ${ }^{\circledR}$.

Penurunan Kadar Kolesterol dihitung berdasarkan rumus :

$$
\% \text { Penurunan Kolesterol }=\frac{\text { Kadar kolesterol akhir }- \text { awal }(\mathrm{mg} / \mathrm{dl})}{\text { kadar kolesterol awal }(\mathrm{mg} / \mathrm{dl})} \times 100 \%
$$

\section{HASIL DAN PEMBAHASAN \\ Hasil Ekstraksi dan Fraksinasi}

Serbuk buncis (300 g) yang diekstraksi dengan etanol, diperoleh ekstrak kental etanol sebanyak 64,04 g dengan rendemen 21,35\%, dan hasil partisinya diperoleh rendemen ekstrak n-heksan $2,7 \%$, etilasetat $4,3 \%$ dan ekstrak air $14 \%$. Persentase rendemen tertinggi adalah fraksi air, hal ini menunjukkan bahwa senyawa polar adalah senyawa utama yang terdapat di dalam buncis.

\section{Hasil Uji Fitokimia}

Hasil uji fitokimia menunjukkan bahwa alkaloid terdapat pada semua ekstrak (etanol, n-heksan, etil asetat dan air). Kandungan flavonoid saponin dan triterpenoid hanya terdapat dalam ekstrak etanol dan air.

\section{Tabel 1. Kandungan Metabolit Sekunder Ekstrak dan Fraksi Buah Buncis}

\begin{tabular}{|c|c|c|c|c|c|}
\hline No & Kandungan & Ekstrak etanol & $\begin{array}{c}\text { Fraksi } \\
n \text {-heksan }\end{array}$ & $\begin{array}{c}\text { Fraksi } \\
\text { etil asetat }\end{array}$ & $\begin{array}{l}\text { Fraksi } \\
\text { Air }\end{array}$ \\
\hline \multirow{4}{*}{1.} & Alkaloid & & & & \\
\hline & Mayer & + & + & + & + \\
\hline & Wagner & - & + & + & + \\
\hline & Dragendorff & - & + & + & + \\
\hline 2. & Flavonoid & + & - & - & + \\
\hline 3. & Tanin & - & - & - & - \\
\hline 4. & Saponin & + & - & - & + \\
\hline 5. & $\begin{array}{l}\text { Steroid / } \\
\text { Terpenoid }\end{array}$ & $\begin{array}{l}+ \\
+\end{array}$ & $+/-$ & $-/-$ & $\begin{array}{l}-1 \\
+\end{array}$ \\
\hline
\end{tabular}

Ket: $(+)=$ positif, $(-)=$ negatif

Fraksi air memiliki kandungan metabolit sekunder lebih lengkap dibanding ekstrak dan fraksi yang lain. Hal ini menunjukkan bahwa kandungan senyawa yang terdapat dalam buncis lebih banyak bersifat polar (Tabel 1).

\section{Pengaruh Pakan Aterogenik terhadap Bobot Badan Tikus}

Berat badan tikus meningkat drastis pada minggu pertama dengan rata-rata peningkatan sebesar +/_ 36 gr, diikuti peningkatan sebesar 4-15 gr/minggu. Pakan aterogenik yang terdiri dari kuning telur dan lemak kambing [11] dapat meningkatkan bobot tikus sebesar 7-14 gr 
18 Lilik Sulastri et al., (Pengaruh Fraksinasi Buncis (Phaseolus vulgaris L.) ...)

selama perlakuan [12]. Kadar kolesterol darah tikus meningkat sebesar $58-67 \mathrm{mg} / \mathrm{dL}$ setelah diinduksi dengan pakan aterogenik. Hal tersebut disebabkan karena telur puyuh mengandung kolesterol paling tinggi setelah otak dan jeroan sapi, yaitu sebesar $364 \mathrm{mg} / \mathrm{gr}$ [13]. Data berat badan tikus hasil induksi dapat dilihat pada Tabel. 2

Tabel. 2 Pengaruh pakan aterogenik terhadap bobot badan tikus

\begin{tabular}{ccccccc}
\hline & & \multicolumn{5}{c}{ Berat Badan $(\mathrm{g})$} \\
\cline { 3 - 7 } No. & Perlakuan & \multicolumn{2}{c}{ Induksi } & \multicolumn{3}{c}{ Perlakuan } \\
\cline { 3 - 7 } & & Sebelum & Sesudah & $\mathrm{H}_{21}$ & $\mathrm{H}_{28}$ & $\mathrm{H}_{35}$ \\
\hline 1 & $\mathrm{~K}-$ & 232,60 & 247,00 & 261,20 & 276,00 \\
2 & $\mathrm{~K}+$ & 186,00 & 221,60 & 230,40 & 237,20 & 244,40 \\
3 & $\mathrm{P} 1$ & 191,00 & 227,20 & 233,80 & 241,80 & 249,80 \\
4 & $\mathrm{P} 2$ & 189,40 & 226,80 & 230,40 & 234,80 & 239,60 \\
5 & P3 & 190,60 & 230,80 & 234,60 & 238,40 & 242,00 \\
\hline
\end{tabular}

Hasil Aktivitas Penurunan Kolestrol Fraksi

Uji aktivitas menyatakan bahwa fraksi air dengan dosis $50 \mathrm{mg} / \mathrm{kg} \mathrm{BB}$ memiliki aktivitas menurunkan kolesterol tikus lebih tinggi dibandingkan fraksi n-heksan dan etil asetat.
Hal tersebut dimungkinkan karena kandungan metabolit sekunder yang bersifat polar memiliki aktivitas lebih tinggi dibandingkan yang semi dan non polar. kadar kolesterol sesuai perlakuan dapat dilihat pada Tabel 3.

Tabel. 3 Rata-Rata Kadar Kolesterol dan Persentase Kenaikan serta Penurunannya pada Uji Pendahuluan

\begin{tabular}{|c|c|c|c|c|c|c|}
\hline \multirow[b]{2}{*}{ No } & \multirow[b]{2}{*}{ Perlakuan } & \multicolumn{5}{|c|}{ Kadar Kolesterol (mg/dl) } \\
\hline & & $\begin{array}{l}\text { Sebelum } \\
\text { Induksi }\end{array}$ & $\begin{array}{l}\text { Sesudah } \\
\text { Induksi }\end{array}$ & $\begin{array}{c}\% \\
\text { Kenaikan }\end{array}$ & $\begin{array}{c}\text { Setelah } \\
7 \text { hari } \\
\text { Perlakuan }\end{array}$ & $\begin{array}{c}\% \\
\text { Penurunan }\end{array}$ \\
\hline 1. & $\begin{array}{c}\text { Fraksi } n \text {-heksan } \\
50 \mathrm{mg} / \mathrm{kg} \mathrm{BB}\end{array}$ & 148,00 & 206,00 & $39,35 \%$ & 192,67 & $6,46 \%$ \\
\hline 2. & $\begin{array}{c}\text { Fraksi etil asetat } \\
50 \mathrm{mg} / \mathrm{kg} \mathrm{BB}\end{array}$ & 143,33 & 208,00 & $45,30 \%$ & 189,67 & $8,84 \%$ \\
\hline 3. & $\begin{array}{c}\text { Fraksi air } \\
50 \mathrm{mg} / \mathrm{kg} \mathrm{BB}\end{array}$ & 143,67 & 211,33 & $47,43 \%$ & 178,33 & $15,57 \%$ \\
\hline
\end{tabular}

Skrining fitokimia fraksi air mengandung flavonoid, flavonoid merupakan senyawa polifenol yang dapat menurunkan kadar kolesterol total dalam darah dengan cara menekan absorbsi kolesterol oleh usus, meningkatkan reaksi pembentukan dan ekskresi asam empedu melalui feses, serta mengurangi kekentalan darah, sehingga mengurangi terjadinya pengendapan lemak pada pembuluh darah, saponin yang terkandung dalam buncis dapat menurunkan penyerapan kolesterol. (14) Berdasarkan data Tabel 3, maka dilakukan uji lanjutan terhadap fraksi air buncis dengan variasi dosis 50, 100 dan $150 \mathrm{mg} / \mathrm{kg} \mathrm{BB}$. Dari perlakuan terlihat bahwa fraksi air dengan dosis $100 \mathrm{mg} / \mathrm{kg}$ BB mampu menurunkan kadar kolesterol sebesar $41,31 \%$ dengan kontrol positif (Simvastatin) sebesar 38,60\%. Sedangkan kelompok kontrol negative (NaCMC) justru mengalami kenaikan kadar kolesterol yang berlanjut, hal tersebut diakibatkan karena pemberian pakan aterogenik dan PTU 0,02\%. Perlakuan fraksi air terhadap penurunan kadar kolesterol dapat dilihat pada Tabel 4. 
19 | Lilik Sulastri et al., (Pengaruh Fraksinasi Buncis (Phaseolus vulgaris L.) ...)

Tabel 4. Aktivitas penurunan Kadar Kolesterol Fraksi Air dengan Variasi Dosis

\begin{tabular}{llccccr}
\hline & & \multicolumn{5}{c}{ Kadar Kolesterol (mg/dl) } \\
\cline { 3 - 6 } No & \multirow{2}{*}{ Perlakuan } & $\mathrm{H}_{0}$ & $\mathrm{H}_{14}$ & $\mathrm{H}_{21}$ & $\mathrm{H}_{28}$ & $\mathrm{H}_{35}$ \\
\cline { 3 - 7 } & & 140,80 & 216,80 & 226,60 & 241,40 & 248,80 \\
& & 155,40 & 230,60 & 200,60 & 172,00 & 141,60 \\
2 & $\mathrm{~K}(+)$ & 144,60 & 224,80 & 199,60 & 172,20 & 148,00 \\
3 & fraksi air 50 mg/kg BB & 147,00 & 227,00 & 191,60 & 164,00 & 133,20 \\
4 & fraksi air 100 mg/kg BB & 161,20 & 227,60 & 185,50 & 152,20 & 125,60 \\
5 & fraksi air 150 mg/kg BB & & & & \\
\hline
\end{tabular}

Ket: $\mathrm{K}(-)=$ kontrol negatif

$\mathrm{K}(+)=$ kontrol positif

$\mathrm{H}_{21}$ = perlakuan minggu ke-1

$\mathrm{H}_{28}=$ perlakuan minggu ke-2

Tabel 4 Menunjukkan bahwa pemberian fraksi air $100 \mathrm{mg} / \mathrm{kg} \mathrm{BB}$ buncis dapat menurunkan kadar kolesterol yang lebih baik dari kontrol

\section{KESIMPULAN}

Hasil penelitian ini dapat disimpulkan bahwa fraksi air buah buncis dengan konsentrasi $100 \mathrm{mg} / \mathrm{kg}$ BB dapat menurunkan kadar kolesterol tikus putih sebesar 41,31\%.

\section{DAFTAR PUSTAKA}

[1] Visavadiya NP. Hypolipidemic And Antioxidant Activities Of Asparagus Asparagus Racemosus In Hyper Cholesteremic Rats Hypercholesteremic Rats. 2005;37(6).

[2] Alam S, Siddiq A, Mohtashhemul Hasan M. Hypolipidemic Effect Of Phaseolus Vulgaris L . At Various Doses And Its Impact On Cardiovascluar. World J Pharm Pharm Sci. 2016;5(11):163-74.

[3] Irma Rosita, Retnosari Andrajati Z. Efek Samping Nyeri Otot Dari Simvastatin Dan Atorvastatin Pada Pasien Jantung RSUD Tarakan. Skripsi Universitas Indonesia. 2014;2-5.

[4] Nugrahani R, Andayani $Y$, Pascasarjana P, Mataram U, Words K. Jurnal Penelitian Pendidikan Ipa. 2016;

[5] Zang L-Y, Cosma G, Gardner H, Shi X,
$\mathrm{H}_{0} \quad=$ sebelum induksi

$\mathrm{H}_{14}=$ setelah induksi

$\mathrm{H}_{35}=$ perlakuan minggu ke- 3

positif (Simvastatin) meskipun hewan uji tersebut mengkonsumsi kolesterol terus menerus selama perlakuan.

Castranova V, Vallyathan V. Effect Of Antioxidant Protection By $\mathrm{P}$-Coumaric Acid On Low-Density Lipoprotein Cholesterol Oxidation. Am J Physiol Physiol. 2017;279(4):C954-60.

[6] Saleem ZM, Ahmed S, Hasan MM. Phaseolus Vulgaris Linn: Botany, Medicinal Uses, Phytochemistry And Pharmacology. World J Pharm Res [Internet]. 2016;5(11):1611-6. Available From: Www.Wjpr.Net

[7] Yang QQ, Gan RY, Ge YY, Zhang D, Corke H. Polyphenols In Common Beans (Phaseolus Vulgaris L.): Chemistry, Analysis, And Factors Affecting Composition. Compr Rev Food Sci Food Saf. 2018;17(6):1518-39.

[8] Ganesan K, Xu B. Polyphenol-Rich Dry Common Beans (Phaseolus Vulgaris L.) And Their Health Benefits. Int J Mol Sci. 2017;18(11).

[9] Wahjuni, Sri., Rustini, N. L., \& Yuliantari P. Pemberian Ekstrak Etanol Buah Buncis (Phaseolus Vulgaris L.) Untuk Menurunkan Kolesterol Total, Low Density Lipoprotein (Ldl) Dan Meningkatkan High Density 
20 | Lilik Sulastri et al., (Pengaruh Fraksinasi Buncis (Phaseolus vulgaris L.) ...)

Lipoprotein (Hdl) Pada Tikus Wistar Diet Tinggi Lemak. 2016;10(Ldl):103-9.

[10] Jannah H, Sudarma Im. Analisis Senyawa Fitosterol Dalam Ekstrak Buah Buncis ( Phaseolus Vulgaris L ). 2013;6(2):70-5.

[11] Gani N, Momuat LI, Pitoi MM. Profil Lipida Plasma Hiperkolesterolemia Pada (Abelmoschus Manihot L .) Tikus Wistar Pemberian Gedi Yang Merah. 2013;2(1):44-9.

[12] Bachmida D. Uji Aktivitas Antikolesterol Ekstrak Etanol Daun Patikan Emas (Euphorbia Prunifolia Jacq.) Pada Tikus Wistar Yang Hiperkolesterolemia. J Mipa Unsrat [Internet]. 2015;4(1):29. Available From:Http://Ejournal.Unsrat.Ac.Id/Index.P $\mathrm{hp} / \mathrm{Jmuo}$
[13] Díaz-Batalla L, Widholm JM, Fahey GC, Castaño-Tostado E, Paredes-López O. Chemical Components With Health Implications In Wild And Cultivated Mexican Common Bean Seeds (Phaseolus Vulgaris L.). J Agric Food Chem. 2006;54(6):2045-52.

[14] Sutjiatmo AB, Sukandar EY, Sinaga R, Hernawati R, Vikasari SN. Efek Antikolesterol Ekstrak Etanol Daun Cerme (Phyllanthus Acidus (L.) Skeels) Pada Tikus Wistar Betina. Kartika J Ilm Farm. 2013;1(1):1-7.

[15] Suthar AC, Banavalikar MM, Biyani MK. Pharmacological Activities Of Genistein, An Isoflavone From Soy (Glycine Max): Part II - Anti-Cholesterol Activity, Effects On Osteoporosis \& Menopausal Symptoms. Indian J Exp Biol. 2001;39(6):520-5. 